\title{
Serine/Threonine-Protein Kinase SIK2
}

National Cancer Institute

\section{Source}

National Cancer Institute. Serine/Threonine-Protein Kinase SIK2. NCI Thesaurus. Code C92520.

Serine/threonine-protein kinase SIK2 (926 aa, 104 kDa) is encoded by the human SIK2 gene. This protein plays a role in protein phosphorylation that affects insulin signaling and mitosis. 